\title{
Non-isolated Boost Charger for the Li-Ion Batteries Suitable for Fuel Cell Powered Laptop Computers
}

\author{
Nguyen Van Sang ${ }^{*}$, Woojin $\mathrm{Choi}^{\dagger}$, and Dae-Wook Kim ${ }^{* *}$

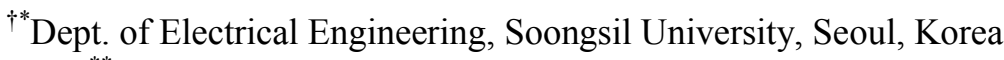 \\ ${ }^{* *}$ Dept. of Economics, Soongsil University, Seoul, Korea
}

\begin{abstract}
The conventional non-isolated boost converter has some drawbacks such as poor dynamic performance and a discontinuous output current, which make it unsuitable for battery charging applications. In spite of its compactness and lightness, it is not preferred as a charger of portable electronic devices. In this paper, a non-isolated boost converter topology for Li-ion batteries suitable for fuel cell powered laptop computers is proposed and analyzed. The proposed converter has an additional inductor at the output to make a continuous output current. This feature makes it suitable for charger applications by eliminating the disadvantages of the conventional non-isolated boost converter mentioned above. A prototype of the proposed converter is built for the Li-ion battery charger of a laptop computer to prove the validity and advantages of the proposed topology.
\end{abstract}

Key words: Battery Charger, Laptop Computer, Non-isolated Boost Converter, Output Inductor, Ripple Current

\section{INTRODUCTION}

These days, portable electronics are more fully-featured than ever before and users are becoming increasingly dependent on these mobile devices and spending ever-longer-periods of time without access to ac sources. However, today's battery technology has only shown limited improvement and is unlikely to meet the ever increasing power demands in the near future. This is the so-called 'power gap', which is the difference between the ever-increasing power demands of portable electronics and the amount of power available in today's battery technologies [1], [2].

Fuel cells are good candidates to replace batteries as power sources for the next generation of portable electronics owing to their high energy density which guarantees a longer operation time. In the future, a tiny fuel cell might replace the batteries in portable electronics such as laptop computers. A compact methanol cartridge can be developed so that it will fit into a small fuel cell package that can power these and other electronic devices for three to five times longer than conventional batteries of the same size and weight. In addition,

Manuscript received Aug. 29, 2012; revised Nov. 9, 2012

Recommended for publication by Associate Editor Joung-Hu Park.

${ }^{\dagger}$ CorrespondingAuthor:cwj777@ssu.ac.kr

Tel: +82-2-820-0652,Fax: +82-2-817-7961,Soongsil University

*Dept. of Electrical Engineering, Soongsil University, Korea

** Dept. of Economics, Soongsil University, Korea it can be accommodated in containers of the same size and weight as conventional batteries, and the fuel cell system can be recharged by refilling a fuel cartridge. Existing research on these battery replacement fuel cells claims that they are safer for the environment than regular batteries. However, in order to use a fuel cell in parallel with a Li-ion battery as a new power source, the conventional power architecture needs to be modified. In this paper, a direct boost charger is introduced to charge the Li-ion batteries of a laptop computer from the fuel cell source. A boost converter can step-up the low voltage of a fuel cell stack to the battery voltage and directly charge the battery thereby reducing power loss. A suitable candidate for this function may be the conventional non-isolated boost converter [3].

The conventional boost converter is a well-known and simple topology which is widely used in many applications despite its limitations in continuous conduction mode (CCM), such as a poor dynamic response and a discontinuous output current, which makes it unsuitable for battery charging applications [4], [5]. It is known that a ripple current can have undesirable effects on a battery such as appreciable heating thereby reducing battery life. A report from a Lithium-ion battery manufacturer shows that appreciable battery heating is caused by the interaction between the ripple current and the internal AC impedance of a Lithium-Ion battery. This will accelerate the degradation of a Lithium-Ion battery since the 


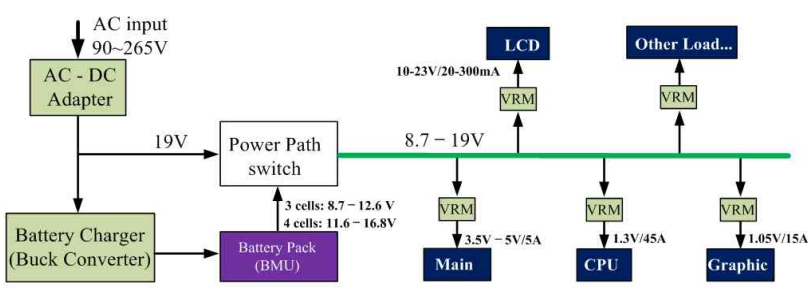

Fig. 1. Current power architecture for laptop.

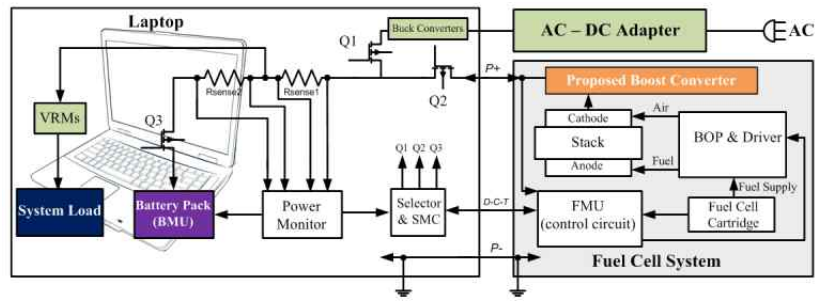

Fig. 2. Proposed power distribution architecture of the fuel cell powered laptop computer.

degradation of battery occurs faster at higher temperatures. This also decreases the efficiency of the battery, resulting in less net current available to be drawn from the battery. Research into the ripple current effects shows that if the battery ripple current exceeds a battery manufacturer's guidelines, the statistically expected life will be reduced by several percentage points [6], [7].

In this paper a non-isolated boost converter for a Li-Ion battery charger suitable for fuel cell powered laptop computers is proposed. To obtain the desired values for the ripple current and the ripple voltage, a supplemental inductor is added at the output of a conventional boost converter to make the output current continuous. An analysis and the design procedure for the proposed charger will be detailed in the following sections.

\section{Proposed POWER DistribUtion ARCHITECTURE FOR FUEL CELL POWERED LAPTOP COMPUTERS}

Fig. 1 shows the fundamental power architecture of today's laptop computers [8], [9].

The CPU Voltage Regulator Module (VRM), the main VRM, the memory VRM, the graphics VRM and the other VRMs are connected after the power selector, which selects between the battery packs and the adaptor. The most widely used battery packs have either three or four cells in series. This creates a voltage range of $8.7[\mathrm{~V}]$ to $16.8[\mathrm{~V}]$. To charge the battery packs, the adapter has a voltage of 19[V]. Today's VRM solutions for laptops are a single phase Buck topology or a multiphase interleaving buck topology. All of the VRMs in a laptop work at wide input voltage from $8.7[\mathrm{~V}]$ to $19[\mathrm{~V}]$. In the Fig. 1 all of the laptop's element as well as the CPU, the main board, the graphic card, the LCD, the memory and the other

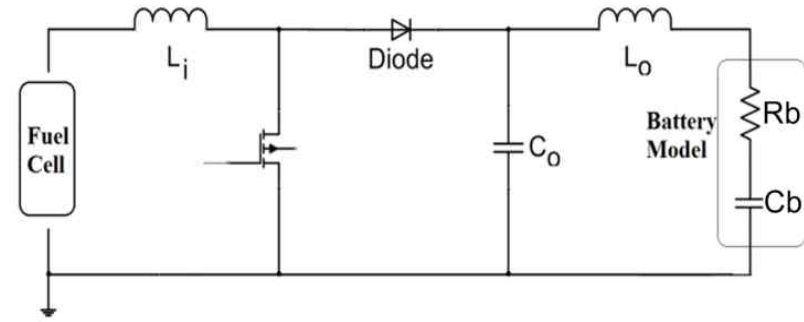

Fig. 3. Proposed boost converter topology suitable for the charge application.

loads are named the system load.

Fig. 2 shows the proposed power distribution architecture for a fuel cell powered laptop computer in detail.

The voltage regulator modules, a battery pack, a battery management unit (BMU) and a buck converter to step down the bus voltage for the VRMs are inside the laptop computer. The VRMs step down the voltage to supply different devices such as the CPU, the main board, the graphics card, the memory, etc. The operating voltages of these devices are normally in the range of $0.6[\mathrm{~V}]$ to $3.3[\mathrm{~V}]$ to increase the speed of the computer. Thus a large voltage reduction is required and therefore, the power conversion efficiency is reduced. The most common method for stepping down a high dc bus distribution system voltage to a lower level is to employ a non-isolated buck converter [1].

In the proposed power architecture, a fuel cell system is located externally to supply power to the laptop when an ac source is not available. The fuel cell voltage is stepped up through the boost converter and directly charges the battery pack. For this architecture, multiple power path switches are used to select the input source. When an ac input is available, switch Q1 is on, which connects the ac-dc converter to the VRM through the buck converter. When an ac input is not available, switch Q2 connects the fuel cell system and the boost charger to the battery pack to charge the battery through switch Q3 and the energy from the battery is used for laptop operation.

\section{Model DeVelopment Of The Proposed BOOST CONVERTER TOPOLOGY}

Fig. 3 shows the proposed boost converter topology for a battery charger.

The proposed topology has an additional inductor at the output of the non-isolated boost converter. The additional inductor (Lo) produces a continuous current and makes the output current ripple smaller. In addition, this front-end inductor is designed to meet the ripple requirement of the fuel cell stack, which is less than $15 \%$ of the DC current. The battery is modeled with an $\mathrm{R}-\mathrm{C}$ series circuit, where $\mathrm{Rb}$ and $\mathrm{Cb}$ represent the equivalent series resistance and the equivalent capacitance of the battery respectively [5]. Generally, a Lithium-Ion battery is charged by the constant 


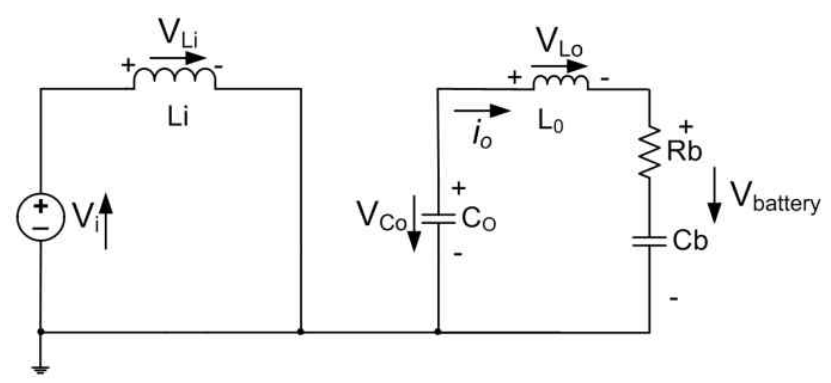

Fig. 4. Closed-switch sub-circuit of the proposed boost converter.

current/constant voltage $(\mathrm{CC} / \mathrm{CV})$ method. The $\mathrm{CC} / \mathrm{CV}$ method is one of the best methods for charging a Li-ion battery because it offers the fastest charging time to fully charge a battery. Charging starts with the CC mode until the battery has reached its maximum voltage. The battery is switched into the $\mathrm{CV}$ mode once the maximum voltage is reached. Meanwhile, in the $\mathrm{CV}$ mode, the charging current is monitored to determine when the charging process can be terminated. Normally, the battery is considered to be fully charged when the charging current drops below 0.1C [10]-[13].

An important issue in the proposed boost charger is the output inductor design to meet the ripple requirements of the battery. In order to derive a suitable inductance value for the output inductor $\left(\mathrm{L}_{0}\right)$ of the proposed boost converter, a steady state analysis is performed when the switch is closed as in Fig. 4.

The voltage loop equation in the rear-end subcircuit can be expressed as (1).

$$
\frac{1}{C_{0}} \int i_{O} d t+L_{O} \frac{d i_{O}}{d t}+R_{b} i_{O}+\frac{1}{C_{b}} \int i_{O} d t=0
$$

The above equation (1) can be rewritten as a second order differential equation, as shown in (2), because $\mathrm{C}_{0}<<\mathrm{C}_{\mathrm{b}}$.

$$
\frac{d^{2} i_{O}}{d t^{2}}+\frac{R_{b}}{L_{O}} \frac{d i_{O}}{d t}+\frac{i_{O}}{C_{O} L_{O}}=0
$$

Thus the output current $i_{O}$ can be expressed as (3).

$$
i_{O}(\mathrm{t})=\Delta I_{\text {output_ripple }} \sin \left(2 \pi f_{s} t+\varphi\right)+I_{O}
$$

By substituting $i_{O}$ into equation (1) during the switch on time, the following is obtained:

$$
-\frac{1}{C_{O}} I_{O} D T+\sqrt{2} \mathcal{L}_{O} \pi f_{s} \Delta I_{\text {output_ripple }}+\left.R_{b} \Delta I_{O}\right|_{t_{1}} ^{t_{1}+D T}=0
$$

Since the ac component of equation (3) is equal to zero at $t_{1}$ and $t_{1}+D T$, the relationship between the output ripple current and the output inductance value can be obtained as (5) by solving (4).

$$
L_{O}=\frac{I_{O} D}{2 \sqrt{2} \pi \Delta I_{\text {output_ripple }} C_{O} f_{S}^{2}}
$$

Where, $I_{0}$ is the charge current, $D$ is the duty cycle, $C_{0}$ is the output capacitor of the converter, $f_{S}$ is the switching frequency, and $\Delta I_{\text {output ripple }}$ is the output ripple current of the converter.

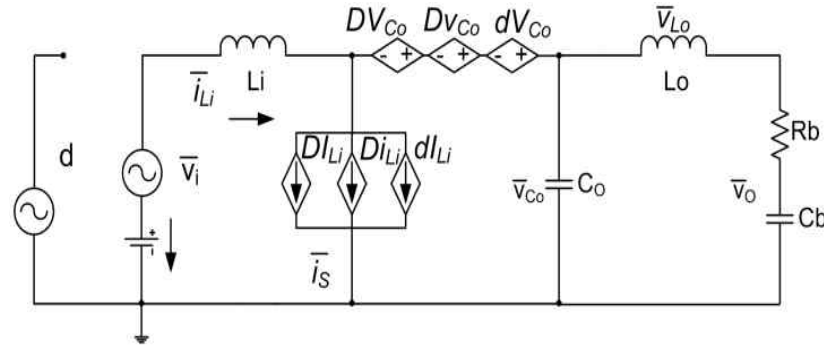

Fig. 5. Large signal model of the proposed boost converter topology.

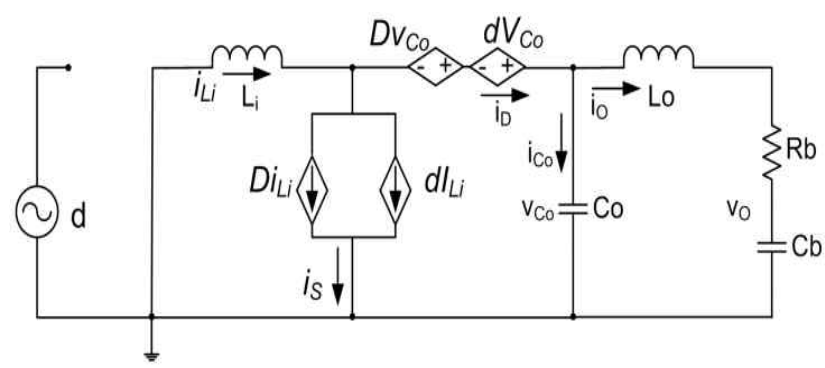

Fig. 6. Small-signal model of the proposed boost converter with a battery load operating in continuous conduction mode.

Thus in order to implement the $\mathrm{CC} / \mathrm{CV}$ mode controller, it is necessary to derive the duty cycle-to-input current and the duty cycle-to-output voltage transfer function of the proposed converter. The average modeling technique is used to develop the average model of the proposed boost charger as shown in Fig. 5[16].

The switch is modeled as a current-dependent current-source in CCM operation, where the total duty cycle is expressed as $\bar{d}=D+\tilde{d}$ and the input inductor current is expressed as $\bar{i}_{L i}=I_{L i}+\tilde{i}_{L i}$.

The resulting switch model becomes $\overline{i_{S}}=\bar{d} \times \bar{i}_{L_{i}}$. The diode can be modeled as a voltage-dependent voltage-source in CCM mode operation and the resulting model becomes $\bar{v}_{D}=d \times \bar{v}_{C o}$. All the double small-signal terms can be neglected when the following conditions are met, $\tilde{i}_{L i}<<I_{L i}, \tilde{v}_{O}<<V_{O} ; \tilde{d}<<D$

Then, the following is obtained:

$$
\begin{gathered}
\overline{i_{S}}=D I_{L_{i}}+D \tilde{i}_{L_{i}}+\tilde{d} I_{L_{i}} \\
\bar{v}_{D}=D V_{C_{O}}+D \tilde{v}_{C_{O}}+\tilde{d} V_{C_{O}}
\end{gathered}
$$

With the results from (6) and (7), the small-signal model of the proposed converter can be redrawn as Fig. 6 .

i) Control-to-output voltage transfer function

By using KCL and KVL, equations (8) and (9) can be obtained.

$$
{\overline{i_{C}}}_{C_{O}}+\bar{i}_{O}=\overline{i_{D}}
$$




$$
-\bar{v}_{i}+\bar{v}_{L_{i}}-\bar{v}_{D}+\bar{v}_{L_{O}}+\bar{v}_{O}=0
$$

Substitution of the small-signal into (10) and (11) yields:

$$
\begin{gathered}
\tilde{i}_{C_{O}}+\tilde{i}_{O}=-I_{L_{i}} \tilde{d}+\tilde{i}_{L_{i}}(1-D) \\
-\tilde{v}_{i}+\tilde{v}_{L_{i}}+\tilde{v}_{L_{O}}(1-D)-D \tilde{v}_{O}-\tilde{d} V_{O}+\tilde{v}_{O}=0
\end{gathered}
$$

From (10) the following is obtained:

$$
\tilde{i}_{L_{i}}=\frac{1}{1-D}\left(s C_{O}\left(\tilde{v}_{L_{O}}+\tilde{v}_{O}\right)+\frac{\tilde{v}_{O}}{R_{b}+\frac{1}{s C_{b}}}+\frac{I_{O}}{1-D} \tilde{d}\right)
$$

The small-signal voltage on the input inductor and the output inductor can be obtained as (13) and (14).

$$
\begin{gathered}
\tilde{v}_{L_{i}}=s L_{i} \tilde{i}_{L_{i}}=\frac{s L_{i}}{1-D}\left(s C_{O}\left(\tilde{v}_{L_{O}}+\tilde{v}_{O}\right)+\frac{\tilde{v}_{O}}{R_{b}+\frac{1}{s C_{b}}}+\frac{I_{O}}{1-D} \tilde{d}\right) \\
\tilde{v}_{L_{O}}=\frac{s L_{O}}{R_{b}+\frac{1}{s C_{b}}} \tilde{v}_{O}
\end{gathered}
$$

By substituting (13) and (14) into (11), the control-to-output voltage transfer function can be obtained as (15).

$$
\begin{aligned}
& \left.G_{v_{0} d}\right|_{\tilde{v}_{i}=0}=\frac{V_{O}}{1-D} \times \\
& \times \frac{1+s\left(C_{b} R_{b}-\frac{L_{i}\left(1-\frac{V_{b}}{V_{b}}\right)}{R_{b}(1-D)^{2}}\right)-s^{2} C_{b} R_{b} \frac{L_{i}\left(1-\frac{V_{b}}{V_{b}}\right)}{R_{b}(1-D)^{2}}}{1+s C_{b} R_{b}+s^{2}\left(C_{b} L_{O}-\frac{C_{b} L_{i}}{(1-D)^{2}}\right)+s^{3} \frac{L_{i} C_{O} C_{b} R_{b}}{(1-D)^{2}}+s^{4} \frac{L_{i} C_{O} C_{b} L_{O}}{(1-D)^{2}}}
\end{aligned}
$$

ii) Control-to-input current transfer function

By using KCL the following is obtained:

$$
\begin{gathered}
\tilde{i}_{L_{i}}=\left(\mathrm{D} \tilde{i}_{L_{i}}+\tilde{d} I_{L_{i}}\right)+\left(\frac{\tilde{v}_{0} Z_{O}}{Z_{b}} S C_{O}+\frac{\tilde{v}_{O}}{Z_{b}}\right) \\
\tilde{v}_{O}=\tilde{i}_{L_{i}}(1-D) Z_{2}-\tilde{d} \frac{I_{L_{i}}}{1-D} Z_{2}
\end{gathered}
$$

where:

$$
\begin{gathered}
Z_{b}=R_{b}+\frac{1}{s C_{b}} \\
Z_{O}=\left(s L_{O}+R_{b}+\frac{1}{s C_{b}}\right) \\
\frac{1}{Z_{2}}=\frac{Z_{O}}{Z_{b}} s C_{O}+\frac{1}{Z_{b}}
\end{gathered}
$$

For the loop with the input inductor, the diode and the output capacitor, KVL can be obtained as:

$$
\begin{gathered}
-\tilde{i}_{L_{i}} s L_{i}+D \tilde{v}_{C_{O}}+\tilde{d} V_{O}-\tilde{v}_{C_{O}}=0 \\
\tilde{v}_{O}=\frac{Z_{b}}{Z_{O}} \frac{\tilde{d} V_{O}-\tilde{i}_{L_{i}} s L_{i}}{1-D}
\end{gathered}
$$

By using (17) and (22) the control-to-input current transfer function is derived as (23)

$$
\begin{aligned}
& \left.G_{i_{i_{i}} d}\right|_{\tilde{v}_{i}=0}= \\
& \frac{\frac{I_{O}}{1-D}+s \frac{2 I_{O} R_{b} C_{b}}{(1-D)}+s^{2}\left(\frac{I_{O} C_{b} R_{b}}{(1-D)}+V_{i n} C_{O} C_{b} R_{b}\right)+s^{3} V_{i n} C_{O} C_{b} L_{O}}{1+s C_{b} R_{b}+s^{2}\left(C_{b} L_{O}+\frac{C_{b} L_{i}}{(1-D)}\right)+s^{3} \frac{L_{i} C_{O} C_{b} R_{b}}{(1-D)}+s^{4} \frac{L_{i} C_{O} C_{b} L_{O}}{(1-D)}}
\end{aligned}
$$

The control-to-output voltage transfer function shows a second order numerator and a forth order denominator. Analyzing the numerator, there are two zeroes, one on the left half plane (LHP) and the other on the right half plane (RHP). For a converter with the RHP zero, the crossover frequency is constrained by the power stage dynamics and it is recommended that the crossover frequency should not exceed one third of the RHP zero frequency for a reasonable ripple. This is especially important for fuel cell applications since the ripple current may have undesirable effects on the fuel cell operation such as power losses and lifetime reduction [15]-[17].

The RHP zero frequency and the maximum crossover frequency can be derived as (24) and (25) by using the system design parameters in Table I, respectively.

$$
\begin{gathered}
f_{\text {RHP-zero }}=\frac{R_{b}}{2 \pi L_{i}\left(1-\frac{V_{b}}{V_{O}}\right)}(1-D)^{2} \approx 2.37 \mathrm{kHz} \\
f_{c}^{\max }=\frac{1}{3} f_{\text {RHP-zero }} \approx 90 \mathrm{~Hz}
\end{gathered}
$$

By using the control-to-output voltage transfer function, the RHP-zero in the Pole-zero map can be seen graphically. This Pole-zero map can appreciate the interrelation of classical-control analysis tools and measures of relative stability. In the map, the blue circles show the poles and the red parallelograms mark the zeros.

As shown in Fig. 7, the control-to-output transfer function has four poles and two zeroes. The control-to-output voltage transfer function has four poles and two zeros.

The RHP zero is located at $2.37[\mathrm{kHz}]$ as calculated by (24). Thus the maximum crossover for the voltage loop should be limited to less than $790[\mathrm{~Hz}]$ as $(25)$.

The Pole-zero map of the control-to-input current transfer function is shown in Fig. 8 and it has four poles and three zeros. Since there is no RHP zero, the current control loop can be designed to have a higher bandwidth. It has been chosen at $6[\mathrm{kHz}]$, which is one tenth of the switching frequency.

As mentioned in the section I, the output ripple value is one of the critical design factors for charge applications, since it affects the reliable operation of a battery and its lifetime. In order to select a suitable value for the output inductor to meet the ripple requirement of the battery during $\mathrm{CC} / \mathrm{CV}$ charge, a 3-D plot was drawn by using (5) to show the relationship between the duty cycle, the output ripple current and the 


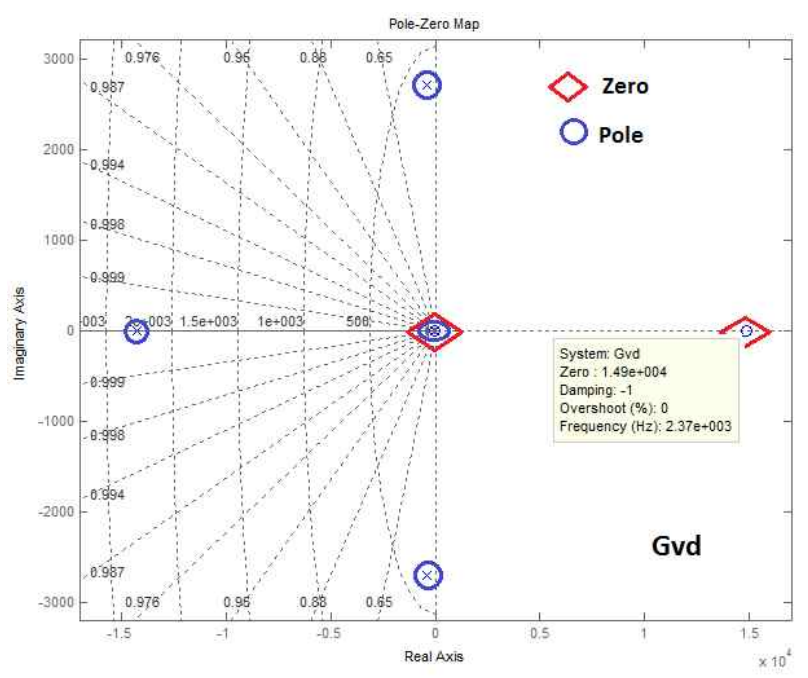

Fig. 7. Pole-zero map of Gvd.

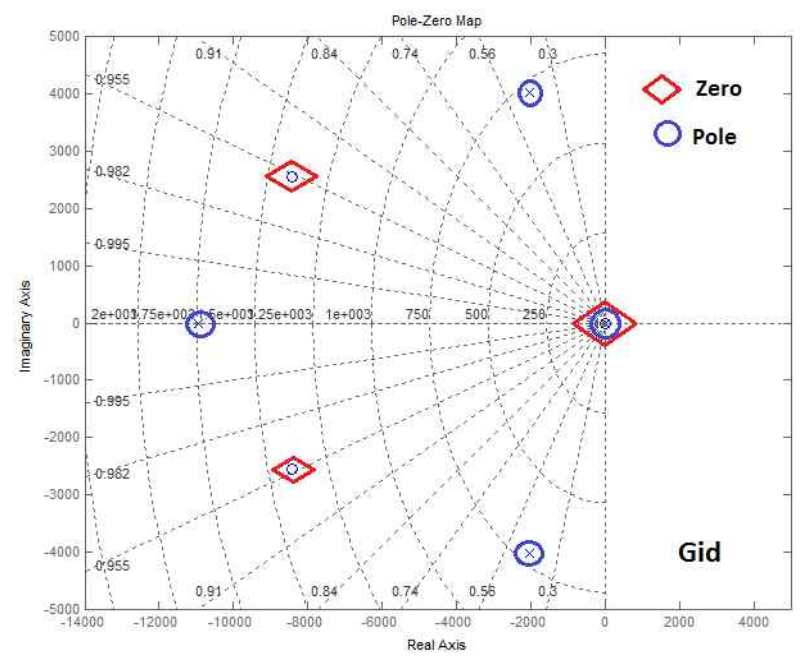

Fig. 8. Pole-zero map of Gid.

output inductance value as in Fig. 9.

In this graph, the duty value varies from 0.44 to 0.55 (corresponding to the minimum and maximum duty cycle in the constant current mode, while the input voltage of the boost converter is $6[\mathrm{~V}]$ and the output voltage varies from $10.8[\mathrm{~V}]$ to 12.6[V]).

In order to find the minimum inductance value to meet the ripple requirement for the battery, Fig. 9 is redrawn for the maximum duty cycle and output current value to show the relationship between output inductance and the output ripple current as Fig. 10. Since the maximum allowable ripple current for the battery used in this paper is $0.26[\mathrm{~A}](0.05 \mathrm{C})$ as in Table $\mathrm{I}, 8.5[\mu \mathrm{H}]$ is the minimum inductance value for the output inductor of the boost charger.

\section{Design the Charge Controller}

In this section, the control algorithm of the proposed boost converter is discussed. Usually the charge requires two

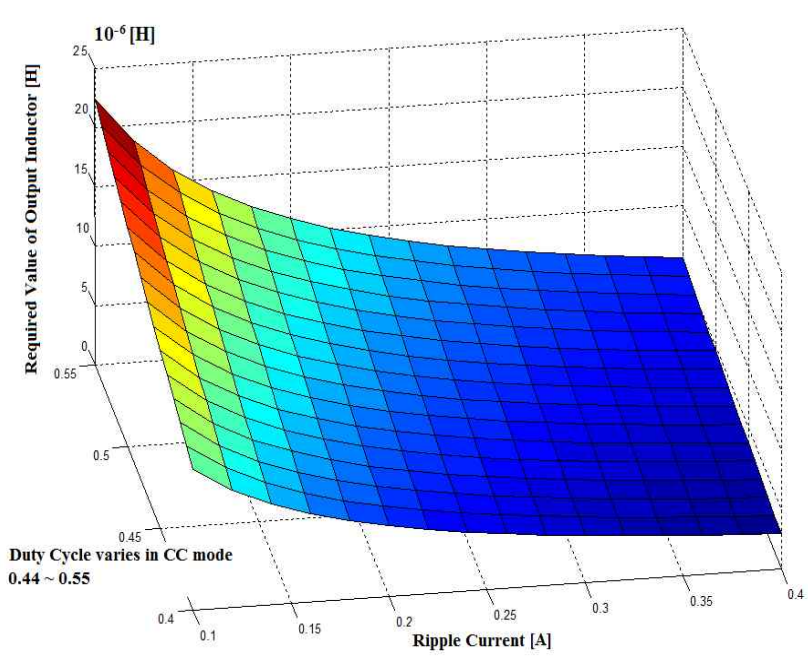

Fig. 9. Relationship between the output ripple current, duty cycle and the output inductance value in CC mode.

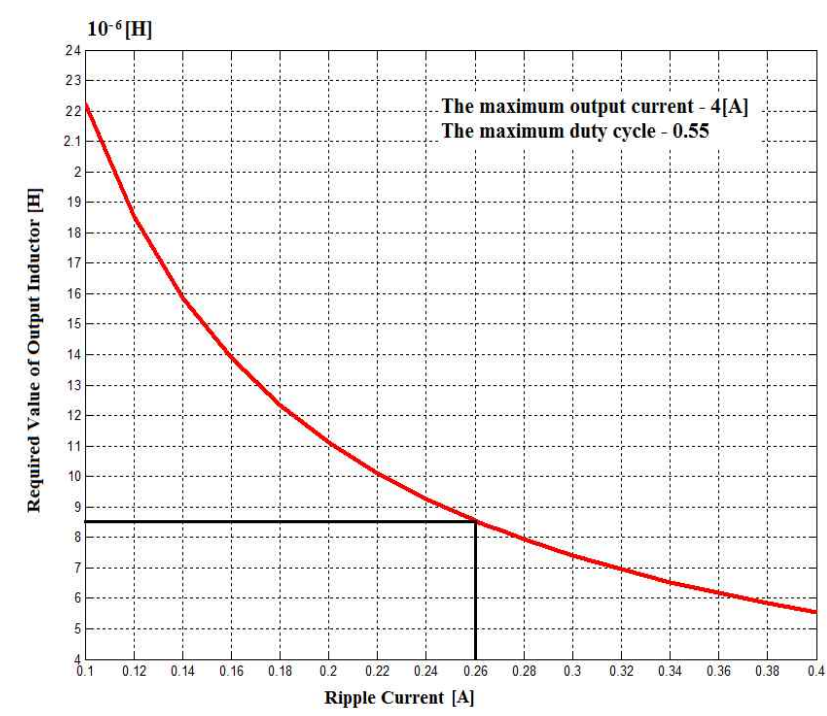

Fig. 10. Relationship between the expected ripple current and the required output inductor in $\mathrm{CV}$ mode.

different control modes, CC \& CV, but in this study a single control loop is used for both control modes to reduce the complexity. Fig. 11 is a block diagram of the battery charge control algorithm using double control loop. It consists of an outer control loop, regulating the converter output voltage $(\mathrm{CV}$ $\mathrm{Mode}$ ) and an inner control loop, serving for the output current control (CC Mode).

In the $\mathrm{CC}$ mode only the charge current is controlled and the output voltage of the converter is the same as the battery voltage. In this case, the battery voltage is slowly increased up to its nominal value as the battery is charged. Once the battery voltage reaches to its nominal value $(12.6 \mathrm{~V}$ in this case), the controller changes its mode to voltage control mode. In this case the output voltage is maintained at its nominal value and the controller changes its duty to maintain the output voltage even if the input voltage from the fuel cell varies. The design 


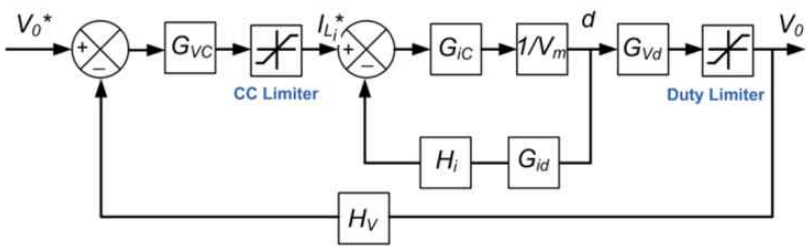

Fig. 11. Block diagram of the battery charge control algorithm using dual control loop.

of the converter and the controller was performed considering input voltage variations, and the charge operation was successfully performed while the converter input voltage (fuel cell output voltage) varied.

In the control, the output voltage $\left(\mathrm{V}_{\mathrm{O}}\right)$ is detected and compared with the reference voltage $\left(\mathrm{V}_{\mathrm{O}} *\right)$. Then the error signal is generated and amplified to generate the current reference $\left(\mathrm{I}_{\mathrm{Li}}{ }^{*}\right)$. Since the charge control starts with constant current (CC Mode), the current reference should be limited at an appropriate value for the inductor current. The current reference $\left(\mathrm{I}_{\mathrm{Li}}{ }^{*}\right)$ is then compared with the measured input current to generate the error signal, which is transmitted to the current controller [18-19-20-21]. The output of the current controller is then compared with the triangular wave to generate the PWM signal for the switch. At this time, the loop gain of the internal current loop and the external voltage loop can be expressed as follows:

The loop gain of the current control loop and voltage control loop can be expressed as (26) and (27), respectively.

$$
\begin{gathered}
T_{i}(\mathrm{~s})=G_{i c} \frac{1}{V_{m}} G_{i d} H_{i} \\
T_{v}(\mathrm{~s})=\frac{G_{v c} G_{i c} \frac{1}{V_{m}} G_{v d} H_{v}}{T_{i}(\mathrm{~s})} 1
\end{gathered}
$$

where, $G_{i c}$ is the current controller gain, $H_{i}$ is the current feedback gain, $1 / \mathrm{V}_{\mathrm{m}}$ is the comparator gain, $\mathrm{G}_{\mathrm{vc}}$ is the voltage controller gain, and $\mathrm{H}_{\mathrm{v}}$ is the voltage feedback gain.

Fig. 12 and Fig. 13 show the design process for the voltage and current controller using a Bode plot. As can be seen in Fig. 11 , the crossover frequency of current controller is $6[\mathrm{kHz}]$. At the crossover frequency, the phase of the open loop transfer function is -93 degree. It can be seen that the phase margin is enough as it is. However, the gain in the low frequency domain is not high enough because of the huge capacitance value of the battery. Therefore, a three-poles, two-zeroes controller is selected to raise the low frequency gain by locating one pole at the origin. The zero is located before the system double pole and the other pole is located before the half of the switching frequency so that the system may become insensitive to high frequency noise. The design also secures a sufficient phase margin of 80 degree at the crossover frequency for the stability of the system.

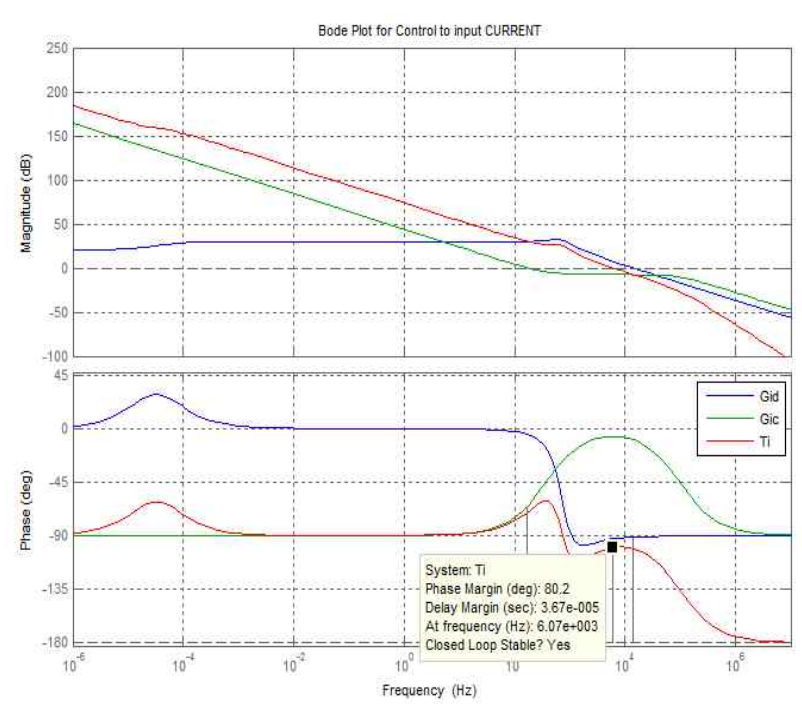

Fig. 12. Design of the current controller using Bode plot.

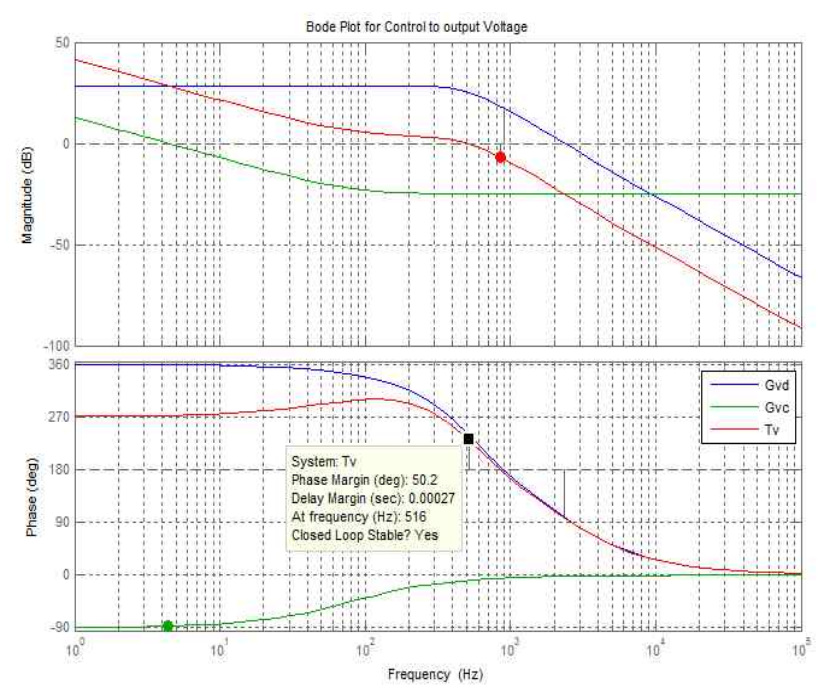

Fig. 13. Design of the voltage controller using Bode plot.

Fig. 13 shows the design of the voltage controller by using a Bode plot. The phase plot of the open loop transfer function at the crossover frequency suggests that it naturally has a sufficient phase margin. Thus a PI controller is used for the voltage control. The design also secures a sufficient phase margin of 50 degree at the crossover frequency and the crossover frequency of the voltage controller is $516[\mathrm{~Hz}]$.

\section{SimUlation}

A PSIM simulation was performed to verify the validity of the developed laptop computer battery charger and its control algorithm. The system parameters for the simulation can be found in Table I.

In the PSIM simulation, a PI controller was used for the current control loop and a Type II controller was used for the 

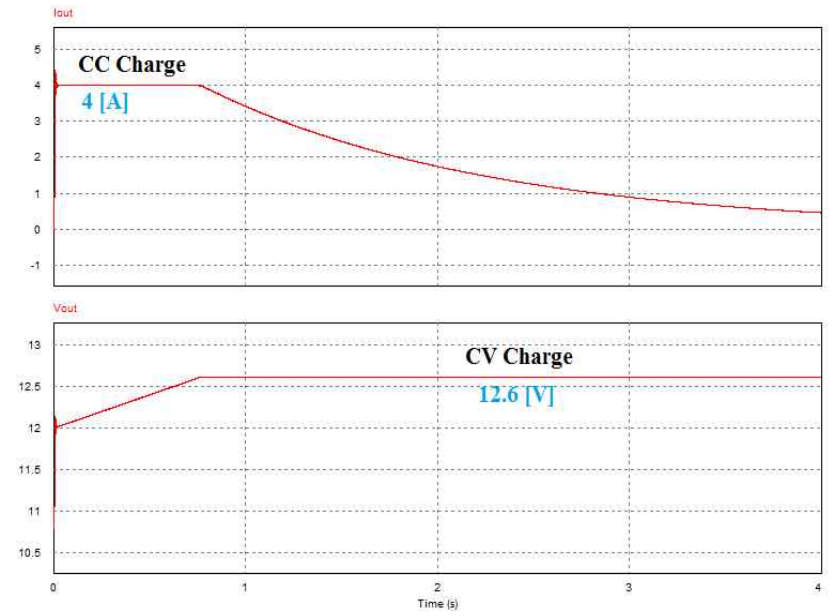

Fig. 14. PSIM simulation results of the proposed boost charger.

TABLE I

SYSTEM PARAMETERS

\begin{tabular}{|c|c|c|}
\hline Input voltage & $\mathrm{V}_{\mathrm{i}}$ & $6-9 \mathrm{~V}$ \\
\hline Output voltage & $\mathrm{V}_{\mathrm{O}}$ & $12.6 \mathrm{~V}$ \\
\hline Output power & $\mathrm{P}_{\mathrm{O}}$ & $50 \mathrm{~W}$ \\
\hline Frequency & $\mathrm{f}_{\mathrm{s}}$ & $60 \mathrm{kHz}$ \\
\hline Input inductor & $\mathrm{Li}$ & $32 \mu \mathrm{H}$ \\
\hline Capacitor & $\mathrm{C}_{\mathrm{O}}$ & $500 \mu \mathrm{F}$ \\
\hline Output inductor & $\mathrm{L}_{\mathrm{O}}$ & $10 \mu \mathrm{H}$ \\
\hline Samsung Battery - 3S2P & \multicolumn{2}{|c|}{1 cell ICR18650 } \\
\hline Nominal Current & $\mathrm{I}_{\text {nominal }}$ & $5.2 \mathrm{~A}$ \\
\hline Charging Current & $\mathrm{I}_{\mathrm{O}}$ & $4 \mathrm{~A}$ \\
\hline Charging Voltage & $\mathrm{V}_{\mathrm{O}}$ & $12.6 \mathrm{~V}$ \\
\hline Battery Initial Volatge & $\mathrm{V}_{\mathrm{b}}$ & $10.8 \mathrm{~V}$ \\
\hline Output Ripple Voltage & $\Delta \mathrm{V}_{\text {output_ripple }}$ & $\begin{array}{c}0.126 \mathrm{~V} \\
(1 \%)\end{array}$ \\
\hline Output Ripple Current & $\Delta \mathrm{I}_{\text {output_ripple }}$ & $\begin{array}{l}0.26 \mathrm{~A} \\
(0.05 \mathrm{C})\end{array}$ \\
\hline $\begin{array}{l}\text { Equivalent capacitance } \\
\text { of the battery }\end{array}$ & $\mathrm{C}_{\mathrm{b}}$ & $9660 \mathrm{~F}$ \\
\hline $\begin{array}{l}\text { Equivalent series resistance } \\
\text { of the battery }\end{array}$ & $\mathrm{R}_{\mathrm{b}}$ & $0.3 \Omega$ \\
\hline
\end{tabular}

voltage control loop. Fig. 14 shows the simulation results of the proposed boost charger in the constant current (CC) mode and in the constant voltage $(\mathrm{CV})$ mode.

From the results, it can be seen that the battery charge current is regulated at a reference value of $4[\mathrm{~A}]$ during the $\mathrm{CC}$ mode. The voltage of the laptop battery gradually increase until it reaches to the upper limit of the charge voltage and then the battery charger automatically shifts to the $\mathrm{CV}$ mode. In the $\mathrm{CV}$ mode, the battery voltage is kept constant at $12.6[\mathrm{~V}]$ and the charge current decreases exponentially.

\section{EXPERIMENTAL RESULTS}

A 50[W] boost charger was implemented for experiments. The validity of the proposed topology and algorithm was then verified by the $\mathrm{CC}$ and $\mathrm{CV}$ Mode charging of an actual battery for a laptop, a three series - two parallel (3S2P) Li-Ion battery

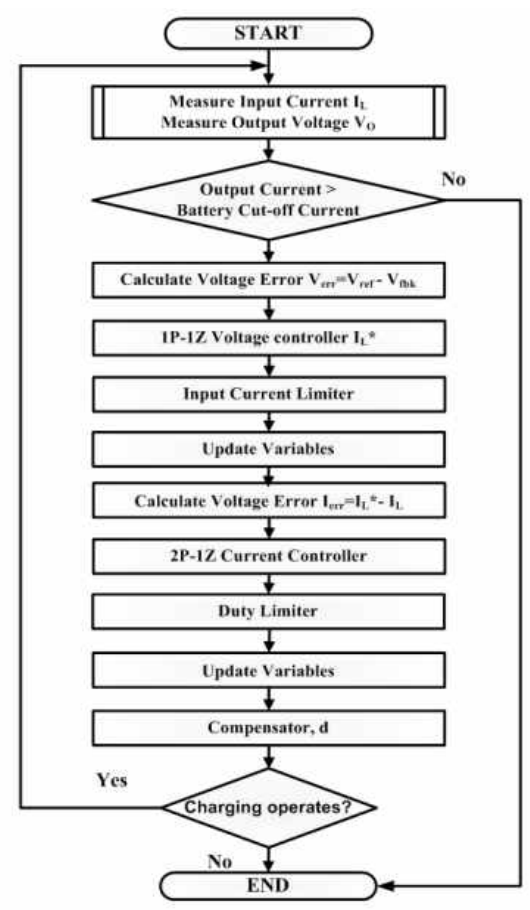

Fig. 15. Flow chart of control algorithm.

pack. The voltage of a single battery by itself is not constant and varies from a minimum of $3.6[\mathrm{~V}]$ to a maximum of $4.2[\mathrm{~V}]$. This creates a $3 \mathrm{~S} 2 \mathrm{P}$ battery voltage range from $10.8[\mathrm{~V}]$ to 12.6[V].

To implement the $\mathrm{CC} / \mathrm{CV}$ mode control algorithm mentioned in the previous section, a digital signal processor (DSP) "TMS320F28335" from TI was used for full digital control of the proposed boost charger and its charge algorithm.

For the digital implementation of the design analog controller, the bilinear transformation is used and the resulting equations are as follows.

$$
\begin{aligned}
& T_{i C}(\mathrm{z})=\frac{0.2571+0.03605 \times z^{-1}-0.221 \times z^{-1}}{1-0.8665 \times z^{-1}-0.1335 \times z^{-2}} \\
& T_{v C}(\mathrm{z})=\frac{5.826-5.778 \times z^{-1}}{1-z^{-1}}
\end{aligned}
$$

A flow chart of the control algorithm implemented in the digital signal processor is shown in Fig. 15.

The battery charge profile of the experimental data is shown in Fig. 16 for both the $\mathrm{CC}$ and $\mathrm{CV}$ charge mode. The charge current is regulated at a reference value of $4[\mathrm{~A}]$ and the voltage of the battery increase gradually until it reaches the nominal battery voltage $12.6[\mathrm{~V}]$. Then the charger changes its mode to $\mathrm{CV}$ mode charge by the control algorithm. In the CV mode, the voltage of the battery is maintained at $12.6[\mathrm{~V}]$ and the current decrease gradually until the battery is fully charged. The efficiency of the charger converter is measured by a digital power meter, "WT110E" from Yokogawa. As can be seen in 


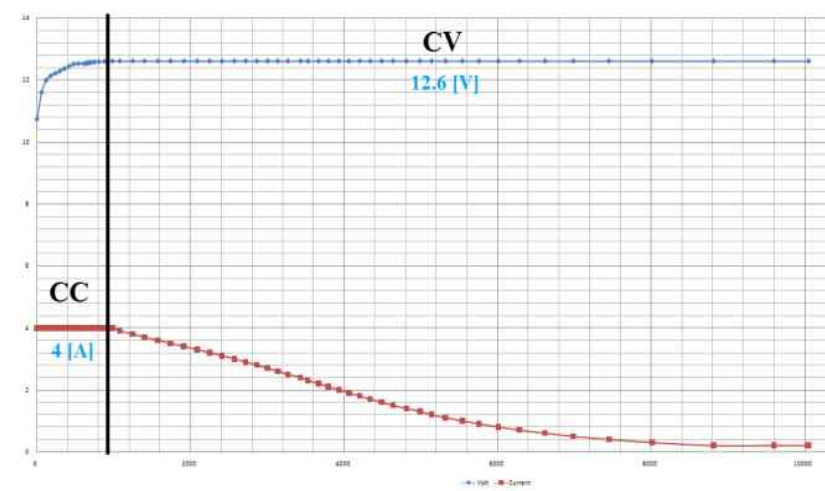

Fig. 16. Battery charge profile of the proposed boost charger.

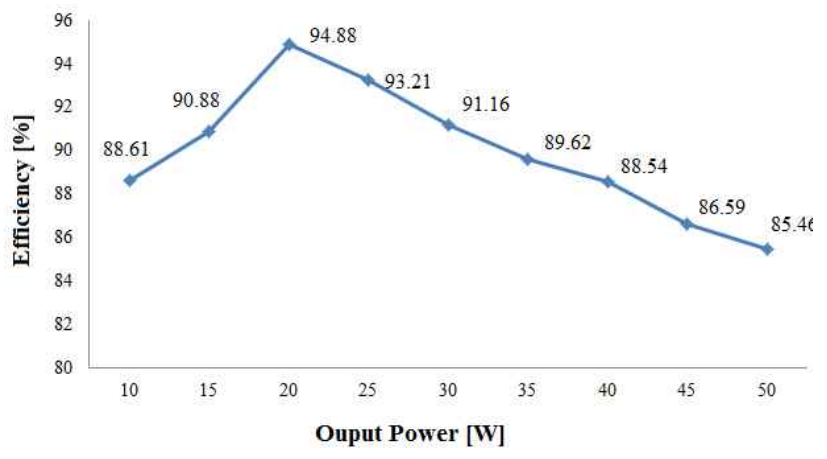

Fig. 17. Efficiency plot of the proposed boost charger.

Fig. 17, the efficiency is $85.46 \%$ under the rated load and the maximum efficiency is $94.88 \%$ under a lighter load.

Fig. 18 and Fig. 19 show the output ripple current of a conventional boost converter and the proposed converter, respectively. From the experimental results, the difference between the values of the ripple current in the conventional boost charger and the proposed boost charger can be seen. As can be seen in the figures, the ripple current was reduced to 0.228 [A] due to an output inductor with a value of $10[\mu \mathrm{H}]$.

Fig. 20 shows the output voltage waveforms of the conventional non-isolated boost converter. As can be seen in the figure, the output voltage ripple exceeds the allowable maximum ripple voltage of the battery $(0.126 \mathrm{~V})$. It can also be seen that there is a $3.6 \mathrm{~V}$ voltage spike due to the switching. However, as can be seen in Fig. 21, the output voltage ripple of the proposed converter is $0.12 \mathrm{~V}$, which is acceptable for a Li-Ion battery, and the voltage spike is also removed by the filter effect caused by the additional inductor and the capacitor inside the battery.

\section{CONCLUSION}

In this paper a non-isolated boost converter suitable for boost charge applications was proposed and its validity was proved by experiments. In addition, the modeling and control of the proposed converter has been detailed. Due to the additional inductor at the output, the charge current becomes

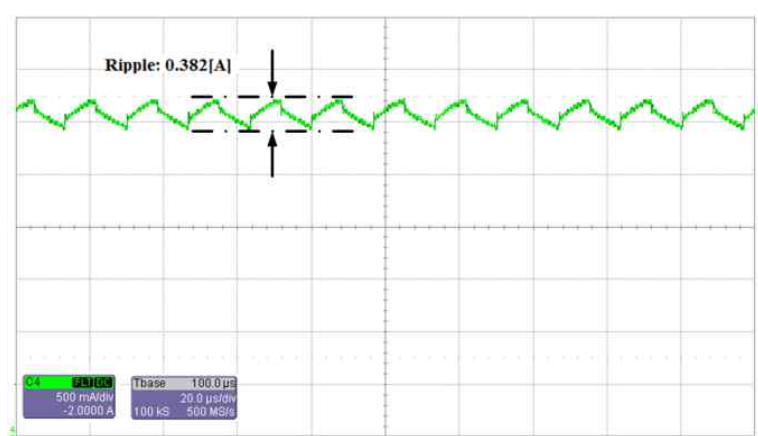

Fig. 18. Output ripple current of the conventional non-isolated boost converter.

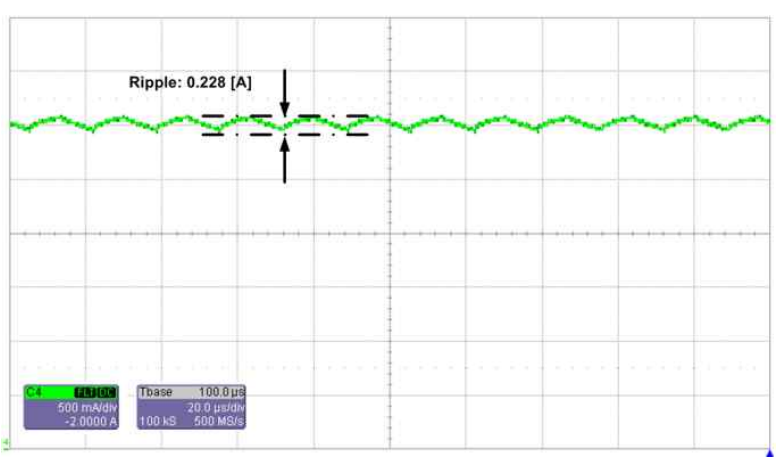

Fig. 19. Output ripple current of the proposed boost converter.

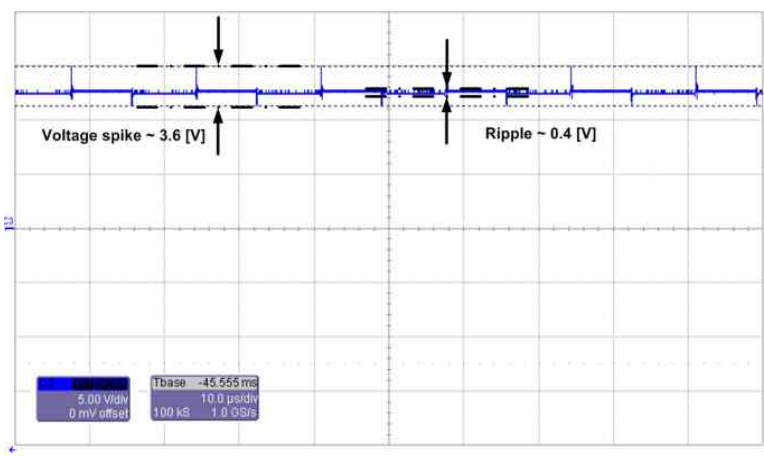

Fig. 20. Output ripple voltage of the conventional non-isolated boost converter.

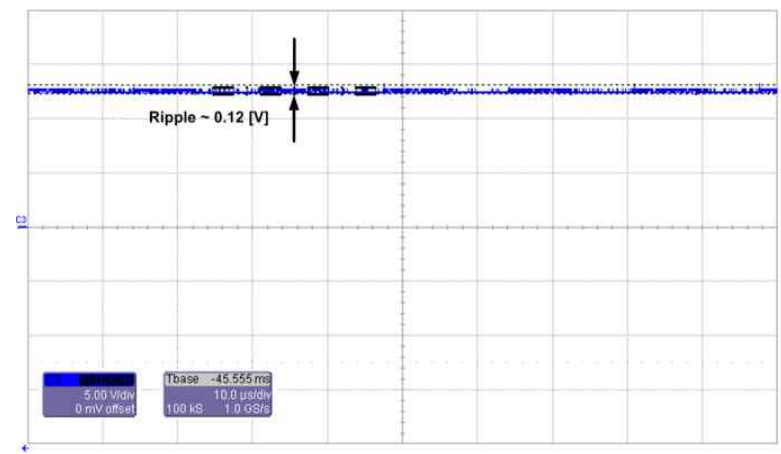

Fig. 21. Output ripple voltage of the proposed boost converter. 
continuous and ripples free, thereby making this converter suitable for battery charge applications.

\section{ACKNOWLEDGMENT}

This work was supported by the Soongsil University Research Fund(2009).

\section{REFERENCES}

[1] M. Harfman-Todorovic, L. Palma, and P. Enjeti, "A hybrid DC-DC converter for fuel cells powered laptop computers," Power Electronics Specialists Conference, 2006. PESC '06. 37th IEEE, pp. 1-5, 2006.

[2] J. Larminie and A. Dicks, Fuel Cell Systems Explained, Wiley, Chichester, England, chap. 2, 2003.

[3] T. Yalcinoz and M. S Alam,“ The dynamic performance of PEM fuel cells under various operating conditions of a laptop computer," EUROCON, 2007. The International Conference on "Computer as a Tool," pp. 1433-1437, 2007.

[4] P. Rueda, S. Ghani, and P. Perol, “A new energy transfer principle to achieve a minimum phase \& continuous current boost converter," Power Electronics Specialists Conference, Vol. 3, pp. 2232-2236, 2004.

[5] X. Zhang, L. X. Wang, and W. X. Shen, "Study on a novel boost battery charger," Industrial Electronics and Applications, 2006 1ST IEEE Conference on, pp. 1-4, May 2006.

[6] EMERSON network power, Effect of AC ripple current on VRLA battery life, A technical note from the Experts in Business-Critical Continuity.

[7] S. Dearborn, Charging Li-ion batteries for maximum run times, Power Electronics Technology Magazine, April 2005.

[8] MAXIM-Integrated (Computer: Notebooks Overview)http://www.maxim-ic.com/solutions/notebook computers/power_management, Jul. 2011.

[9] M. Xu, Y. Ying, and F. C. Lee, "High power density, high efficiency system two-stage power architecture for laptop computers," Power Electronics Specialists Conference, 2006. PESC '06. 37th IEEE, pp. 1-7, 2006.

[10] A. Jossen, "Fundamentals of battery dynamics," Journal Power Sources, Vol. 154, No. 2, pp. 530-538, Mar. 2006.

[11] G. Sikha, P. Ramadass, B.S. Haran, R. E. White, and B. N. Popov, "Comparison of the capacity fade of Sony US 18650 cells charged with different protocols," Journal of Power Sources, Vol. 122, No. 1, pp. 67-76(10), Jul. 2003.

[12] B.R. Lin, H.K. Chiang, and C.Y. Cheng, "Interleaved DC-DC converters with partial ripple current cancellation," Journal of Power Electronics, Vol.12, No.2, pp.249-257, Mar. 2012.

[13] H.L. Do, "Single-switch buck converter with a ripple-free inductor current," Journal of Power Electronics, Vol. 11, No. 4, pp.507-511, Jul. 2011.

[14] B. Bryantand M. K. Kazimierczuk, "Small-signal duty-cycle to inductor current transfer function for boost PWM DC-DC converter in continuous conduction mode," Circuits and Systems, 2004. ISCAS '04. Proceedings of the 2004 International Symposium on, Vol. 5, pp. V-385-V388, 2004.

[15] A. Fernandez, F. Tonicello, J. Aroca, and O. Mourra, "Battery discharge regulator for space applications based on the boost converter," Applied Power Electronics
Conference and Exposition (APEC), 2010 Twenty-Fifth Annual IEEE, pp. 1792-1799, 2010.

[16] R. Ridley, "Switching Power Magazine," pp.22-25, Jan. 2001.

[17] D. Diaz, O. Garcia, J. A. Oliver, P. Alou, and J. A. Cobos, "Analysis and design considerations for the right half -plane zero cancellation on a boost derived $\mathrm{dc} / \mathrm{dc}$ converter," Power Electronics Specialists Conference, 2008. PESC 2008. IEEE, pp. 3825-3828, 2008.

[18] X. Huang, X. Wang, T. Nergaard, J.S. Lai, X. Xu, and L. Zhu, "Parasitic ringing and design issues of digitally controlled high power interleaved boost converters," IEEE Trans. Power Electron., Vol. 19, No. 5, pp. 1341-1352, Sep. 2004.

[19] P. Cooke, "Modeling average current mode control," Applied Power Electronics Conference and Exposition, 2000. APEC 2000. Fifteenth Annual IEEE, Vol. 1, pp. 256-262, 2000.

[20] T.H. Kim, S.J. Kim, and W.J. Choi, "Design and control of the phase shift full bridge converter for the on-board battery charger of electric forklifts," Journal of Power Electronics, Vol.12, No.1, pp.113-119,Jan. 2012.

[21] R. D. Middlebrook, "Topics in multiple-loop regulators and current-mode programming," IEEE Trans. Power Electron., Vol.PE-2, No. 2, pp. 109-124, Apr. 1987.

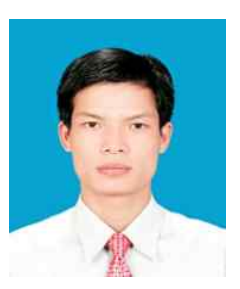

Nguyen Van Sang was born in Hanoi, Vietnam, in 1985. He received his B.S. in Electrical Engineering fromHanoi University of Technology, Hanoi, Vietnam, in 2008. He is currently working toward his M.S. at Soongsil University, Seoul, Republic of Korea. His current research interests include battery chargers and dc-dc converters.

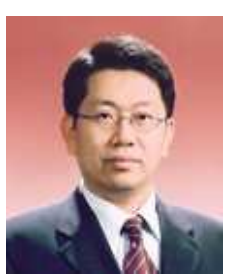

Woojin Choi was born in Seoul, Republic of Korea, in 1967. He received his B.S. and M.S. in Electrical Engineering from Soongsil University, Seoul, Republic of Korea, in 1990 and 1995, respectively. He received his Ph.D. also in Electrical Engineering from Texas A\&M University, USA, in 2004. From 1995 to 1998, he was with Daewoo Heavy Industries as a Research Engineer. In 2005 he joined the School of Electrical Engineering, Soongsil University. His current research interests include the modeling and control of electrochemical energy sources such as fuel cells, batteries and supercapacitors, power conditioning technologies used in renewable energy systems, and dc-dc converters for fuel cells and hybrid electric vehicles.

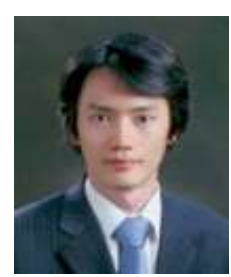

Dae-Wook Kim was born in Seoul, Republic of Korea, in 1973. He received his B.A. in Economics from Yonsei University, Seoul, Republic of Korea, in 1999. He received his $\mathrm{Ph}$.D. also in Economics from University of California at Davis, USA, in 2004. From 2004 to 2007, he worked for the Korea Institute for Industrial Economics and Trade as a Research Fellow. In 2007, he joined the Department of Economics, Soongsil University, Seoul, Republic of Korea. His current research interests include energy economics with a particular interest in market structure and competition in energy industries. 